\title{
Fate of organic pollutants in a pilot-scale membrane bioreactor-nanofiltration membrane system at high water yield in antibiotic wastewater treatment
}

\author{
Jianxing Wang, Yuansong Wei, Kun Li, Yutao Cheng, Mingyue Li \\ and Jianguo $\mathrm{Xu}$
}

\begin{abstract}
A double membrane system combining a membrane bioreactor (MBR) with a nanofiltration (NF) membrane at the pilot scale was tested to treat real antibiotic wastewater at a pharmaceutical company in Wuxi (China). The water yield of the pilot system reached over $92 \pm 5.6 \%$ through recycling the NF concentrate to the MBR tank. Results showed that the pilot scale system operated in good conditions throughout the entire experiment period and obtained excellent water quality in which the concentrations of chemical oxygen demand and total organic carbon were stable at 35 and $5.7 \mathrm{mg} / \mathrm{L}$, respectively. The antibiotic removal rates of both spiramycin (SPM) and new spiramycin in wastewater were over $95 \%$. Organics analysis results showed that the main organics in the biological effluent were proteins, soluble microbial by-product-like, fulvic acid-like and humic-like substances. These organics could be perfectly rejected by the NF membrane. Most of the organics could be removed through recycling NF concentrate to the MBR tank and only a small part was discharged with NF concentrate and permeate.
\end{abstract}

Key words | antibiotic wastewater, MBR-NF, organic pollutants, water yield

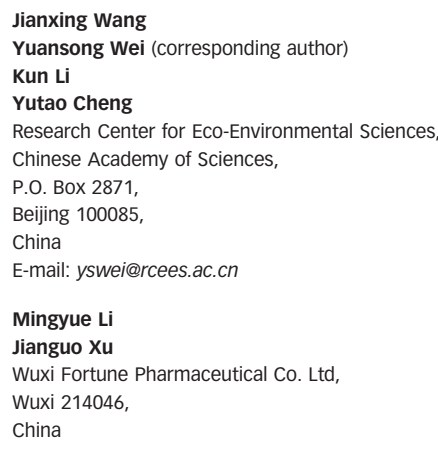

\section{INTRODUCTION}

The pharmaceutical industry of China has experienced rapid development, and become one of the major industries discharging industrial wastewater and pollutants since the year 2000. Among wastewater discharged from the pharmaceutical industry, the wastewater from antibiotic production is not only large in amount, but also difficult to treat because of high concentrations of recalcitrant pollutants (Chelliapan et al. 2006; Wang et al. 2009a). The main pollutants in antibiotic wastewater are organic matters, including antibiotics and their intermediates, organic menstruum and small molecule acids. Nowadays most of this kind of wastewater is treated by conventional biological treatment processes, but the effluent still shows lots of color and contains recalcitrant organic compounds (Xing \& Sun 2009).

Furthermore, it has been reported that concentrations of antibiotic drugs from ng/L up to a few $\mu \mathrm{g} / \mathrm{L}$ have been detected in wastewater and surface waters (Amin et al. 2006). Worse still, certain point sources such as pharmaceutical production facilities may have a much higher antimicrobial concentration of effluent up to the order of a doi: $10.2166 /$ wst.2013.789 few $\mathrm{mg} / \mathrm{L}$ (Amin et al. 2006; Kummerer 200I). It is worrying that the incidence of antibiotic-resistant bacteria (ARB) has increased. This is believed to result from the use of antibiotics (Alexy et al. 2004), therefore antibiotic wastewater treatment is of great concern due to the presence of ARB and antibiotic resistance genes which may pose a great potential health risk to humans (Elmolla \& Chaudhuri 20II). Thus, the removal of antibiotics from wastewater is a challenge is given more and more attention. Along with increasingly stringent requirements in the pharmaceutical wastewater discharge standards, there is a great need to develop new technologies and advanced methods for improving pharmaceutical wastewater treatment and removing the pollutants in wastewater.

Recently, dual membrane systems consisting of membrane bioreactor (MBR) and reverse osmosis (RO) or nanofiltration (NF) have received much attention as promising alternative treatments to remove trace organic contaminations or promote water recycling in view of the advantages of MBR and RO/NF (Choi et al. 2008; Alturki et al. 20I0; Joss et al. 20II). However, most of the dual 
membrane systems have been used for municipal wastewater treatment and reclamation, and there are few reports of two or more membrane systems being used in treating industrial wastewater. Meanwhile, the treatment of $\mathrm{NF} / \mathrm{RO}$ concentrate in these double membrane systems is still a real challenge. Moreover, most of the dual membrane system adopted RO for the advanced treatment, whereas NF has been rarely used. In addition, as the antibiotic wastewater was mainly polluted by organic matter, it is important that their fate in the treatment plant is understood. However, this research is also scarce in the literature.

In this study, a pilot-scale MBR-NF installed at an antibiotic wastewater treatment plant in Wuxi, China was tested to treat the real antibiotic wastewater. Part of the NF concentrate was recycled back into the MBR tank to get a high water yield. The removal of organics and antibiotics from wastewater were investigated and the fate of organic pollutants in the process was identified by fluorescence excitation-emission matrix (EEM) spectrometry method.

\section{MATERIALS AND METHODS}

\section{Wastewater characteristics}

The feed water of the pilot MBR-NF system was the effluent of the anaerobic process from a wastewater treatment station at a pharmaceutical company in Wuxi (China) producing spiramycin (SPM). The concentrations of chemical oxygen demand (COD), total organic carbon (TOC), SPM and new spiramycin (NSPM) were 1,384 $\pm 299,239 \pm 93$, $2.78 \pm 0.08,1.35 \pm 0.04 \mathrm{mg} / \mathrm{L}$, respectively.

\section{Pilot MBR-NF system}

The pilot MBR-NF system consists of a MBR followed by a setup of NF. The MBR was equipped with flat-sheet membrane modules $\left(0.1 \mu \mathrm{m}\right.$ pore size at $34 \times 0.25 \mathrm{~m}^{2}$, polyvinylidene fluoride; Sinap, China) immersed in the aerobic tank at $1.5 \mathrm{~m}^{3}$ of effective volume. Intermittent membrane suction was applied with $6 \mathrm{~min}$ of suction followed by 2 min idle. During operation, $\mathrm{Na}_{2} \mathrm{CO}_{3}$ was added into the MBR tank to keep the $\mathrm{pH}$ at $7.09 \pm 0.4$.

The NF unit consisted of two polyamide thin-film composite membrane modules (200 Da of MWCO, $5.2 \mathrm{~m}^{2}$ of surface area; Filmtec ${ }^{\text {TM }}$ NF90-2540, Dow, USA) operated in parallel. The NF unit was operated at a transmembrane pressure (TMP) of 7.5 bar at a cross-flow rate of $2.0 \mathrm{~m}^{3} / \mathrm{h}$. The NF membranes were chemically cleaned every 9 or 10 days, including an acid cleaning at $\mathrm{pH}$ 2.0-2.5 diluted by concentrated hydrochloric acid $(\mathrm{HCl}, 37 \%)$ and followed by a basic cleaning at $\mathrm{pH} 10.0-10.5$ with $0.3 \mathrm{wt} \%$ sodium dodecyl sulfate (NaDS) $\left(\mathrm{Cl}_{2} \mathrm{H}_{25} \mathrm{SO}_{4} \mathrm{Na}\right)$.

During operation, the NF concentrate was firstly stored in a buffer tank and then returned to the aeration tank of the MBR at the set water yield of 90\%. Figure 1 shows a schematic outline of the pilot MBR-NF system. Part of the produced NF permeate was stored in a tank for NF chemical cleaning. The flow rate of the pilot MBR-NF system was $0.52 \pm 0.08 \mathrm{~m}^{3} / \mathrm{d}$.

\section{Analytical methods}

$\mathrm{COD}_{\mathrm{Cr}}$ was determined according to Standard Methods (APHA 1998). TOC was determined by a TOC-VCPH analyzer (Shimadzu, Japan).

Concentrations of SPM and NSPM were measured by an ultra-performance liquid chromatography with tandem mass spectrometry (Waters Corp., USA). Each sample at $0.5 \mathrm{~mL}$ was extracted with $1.0 \mathrm{~mL}$ butyl acetate by vortexing for $1 \mathrm{~min}$, and then centrifugation at 10,000 r/min for $3 \mathrm{~min}$. The same extraction procedure was repeated twice, and then all the supernatant was combined and dried under nitrogen. Finally, the sample was dissolved in an acetonitrile/water

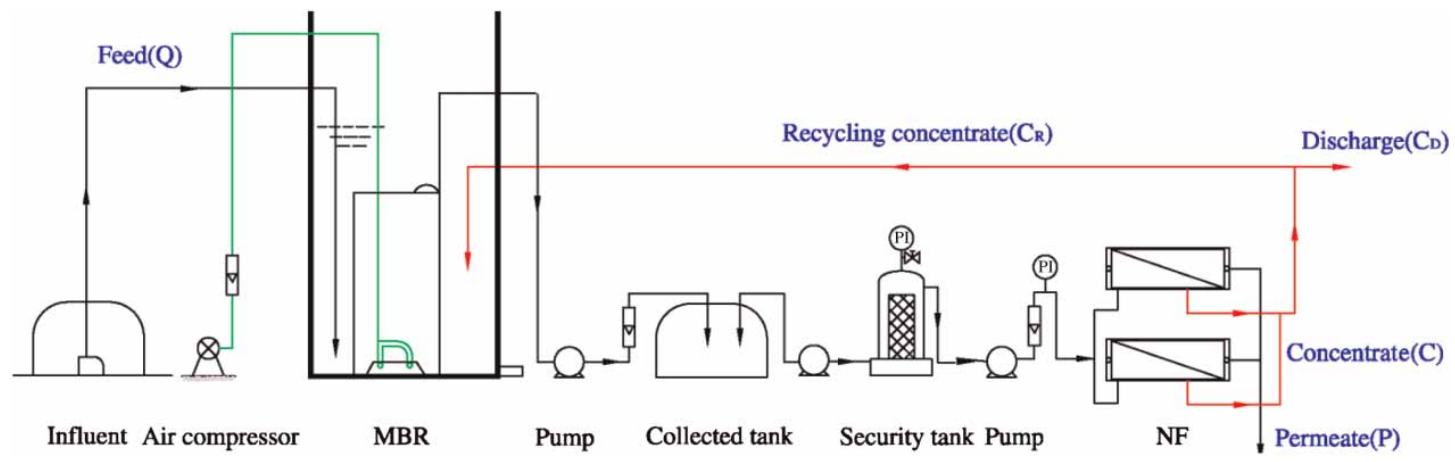

Figure 1 | Schematic outline of the pilot MBR-NF. 
solution $(1: 1, v / v)$ and then diluted to an appropriate concentration for determination. All samples were analyzed in triplicate.

Organic forms were determined by a three-dimensional fluorescence EEM spectrometry (3D-EEM) method. A fluorescence spectrophotometer (F-7000; Hitachi, Japan) was used to investigate major components and the complexity of the organic matter that was contained in the feed and treated water. In this study, the 3D-EEM spectra were obtained by collecting excitation and emission spectra of a natural organic matter source over a range, including excitation wavelength (Ex) between 200 and $400 \mathrm{~nm}$, emission wavelength (Em) between 250 and $550 \mathrm{~nm}$, at $5 \mathrm{~nm}$ sampling intervals. The instrumental parameters were excitation and emission slits, $5 \mathrm{~nm}$; response time, $0.01 \mathrm{~s}$; and scan speed, 2,400 nm/min. Data were analyzed with Sigma Plot software (Sigma Software Inc., USA). Spectral subtraction was performed to remove blank spectra mainly caused by Raman scattering.

\section{RESULTS AND DISCUSSION}

\section{Performance of the MBR-NF pilot system}

Figure 2(a) shows the changes of flux and TMP of the MBR over the entire experiment period. It is apparent that TMP was stable at a pressure of -4.5 to $-7.5 \mathrm{kPa}$ without any chemical cleaning, which demonstrated that the MBR operation was in good condition and membrane fouling was under control. The abrupt increase of the membrane flux from 6-10 days was due to the fluctuation of the pilot system during the start-up period. As shown in Figure 2(b), the NF permeability declined sharply in the first 15 days and was then maintained stable. The decrease in permeability of the NF in the initial period primarily might be attributed to the increase of salt concentration and accumulation of the pollutants in the virgin membrane. In the start-up days, the water yield was relatively low because the MBR-NF system was being adjusted to stabilization. However, in the stable period, water yield of the pilot MBR-NF was over $92 \pm$ $5.6 \%$, which was similar to Joss's (Joss et al. 20II) study of a pilot MBR-NF treating municipal wastewater. This high water yield of the pilot MBR-NF will correspondingly result in an even lower amount of concentrate for disposal.

\section{COD and TOC removal}

Figure 3 shows changes of COD and TOC concentrations of the pilot MBR-NF system. It is clear that the MBR-NF system had excellent pollutant removal performance though there was a large fluctuation of the pollution concentration in the influent. The COD and TOC concentrations of the NF permeate were stable at 35 and $5.7 \mathrm{mg} / \mathrm{L}$, respectively, which could meet with 'The reuse of urban recycling water - Water quality standard for industrial uses' (GB21903-2008, China). This result was consistent with the report that NF membranes could effectively remove the COD and colored components in biological wastewater treatment effluent (Choi et al. 2008).

Moreover, Figure 3 also shows higher concentrations of COD and TOC in the NF concentrate because of the rejection of the NF membrane. However, the MBR effluent and NF permeate were stable through recycling the NF concentrate to the MBR tank. This result demonstrated that the organics in the NF concentrate could be further degraded in the MBR tank and the pilot system could reach balance.
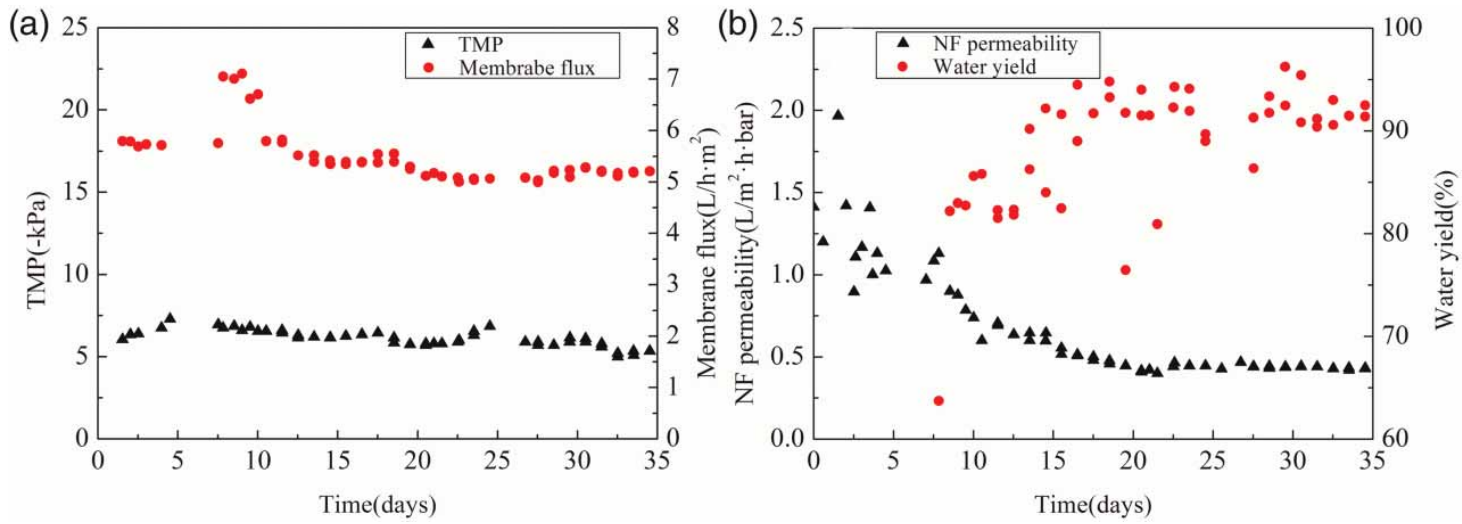

Figure 2 | Performance of the pilot MBR-NF in the test period: (a) MBR, (b) NF. 


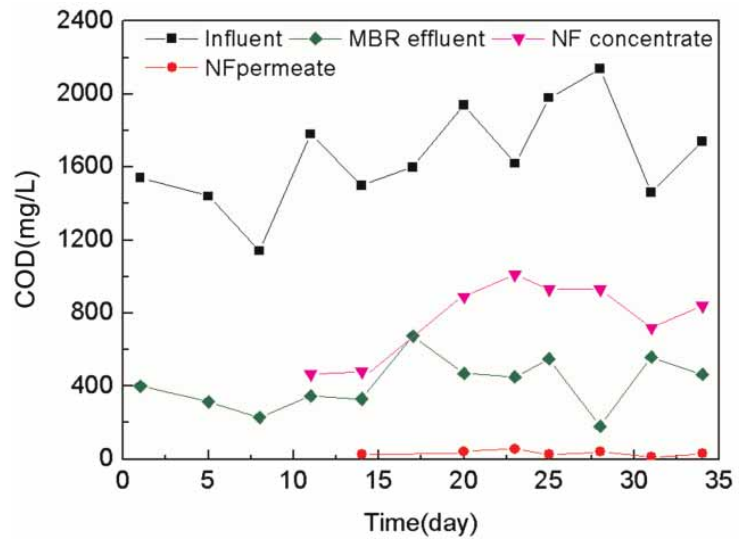

Figure 3 | Changes of COD and TOC in the pilot MBR-NF system.

\section{Antibiotics removal}

SPM and NSPM were the two main antibiotics in the test wastewater. The concentrations of the two antibiotics were investigated along the pilot system. As shown in Figure 4, there were high concentrations of SPM and NSPM in the influent. After treatment by the MBR unit, the removal rates of the two antibiotics reached 51-55\%, which demonstrated that the biological methods could not remove the antibiotics effectively, and advanced treatment would be needed. With NF treatment, the removal rates of both SPM and NSPM were over 95\%. This result was consistent with Kim's research (Kim et al. 2007). Sahar et al. also demonstrated that the RO membrane cannot serve as an absolute barrier to organic micropollutants such as macrolides (Sahar et al. 20II). In addition, Figure 4 shows that most of the SPM and NSPM were rich in NF concentrate which led to higher concentrations of it. However, the antibiotics in the NF concentrate could be further removed in the MBR through recycling.

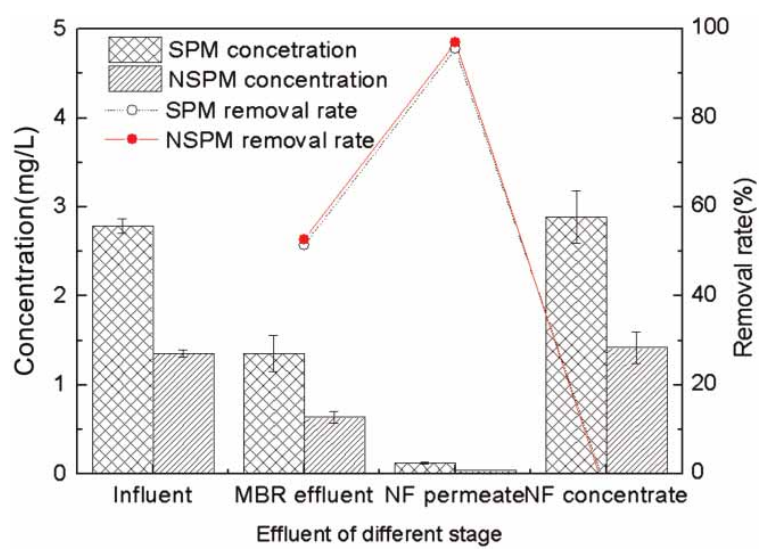

Figure 4 | Changes of antibiotic concentrations in the pilot MBR-NF system.
As mentioned above, most of the organic pollutants (COD, TOC and antibiotics) could be removed through recycling the NF concentrate in the MBR in this pilot system; only a small part was discharged with the NF concentrate and permeate (water yield of 90\%). These results clearly showed that recycling of the NF concentrate had no significant impact on the performance of the pilot MBR-NF treating antibiotic wastewater.

\section{Fate of organic pollutants}

The 3D-EEM spectra are a collection of a series of emission spectra over a range of excitation wavelengths, which can be used to identify the fluorescent compounds present in complex mixtures (Wang et al. 2009b). According to the research (Chen et al. 2003), the EEM spectra could be divided into five regions, including humic acid-like, fulvic acid-like, tyrosine-like, tryptophan-like, and soluble microbial byproductlike organics, respectively (Table 1). The tyrosine-like and tryptophan-like organics can be summarized as proteinlike organics. As mentioned above, the main pollutants in antibiotic wastewater were organic matters. After treatment by biological methods, the contents and forms might be changed. To evaluate the forms and fate of organics along the pilot MBR-NF system, the changes of 3D-EEMs at each stage of wastewater were analyzed and the results are shown in Figure 5 and Table 1.

As shown in Figure 5, strong aromatic tyrosine-like fluorescence and soluble microbial by-product-like fluorescence, which had maximum peaks at the Ex/Em of 225/335 nm (peak A) and 275/340 nm (peak B) (Chen et al. 2003), were found in the influent. This might be partly because the antibiotic was produced by a fermentation process, there were a lot of microorganism metabolites in the antibiotic 
Table 1 | EEM peaks and intensities of the pilot MBR-NF feed and permeate

\begin{tabular}{|c|c|c|c|c|c|c|c|c|c|c|}
\hline \multirow[b]{2}{*}{ EEM region } & \multirow[b]{2}{*}{$\operatorname{Ex}(\mathrm{nm})$} & \multirow[b]{2}{*}{$\mathrm{Em}(\mathrm{nm})$} & \multicolumn{2}{|l|}{ Influent } & \multicolumn{2}{|c|}{ MBR effluent } & \multicolumn{2}{|c|}{ NF concentrate } & \multicolumn{2}{|c|}{ NF permeate } \\
\hline & & & Ex/Em & $\begin{array}{l}\text { Inten. } \\
\text { Max. }\end{array}$ & Ex/Em & $\begin{array}{l}\text { Inten. } \\
\text { Max. }\end{array}$ & Ex/Em & $\begin{array}{l}\text { Inten. } \\
\text { Max. }\end{array}$ & Ex/Em & $\begin{array}{l}\text { Inten. } \\
\text { Max. }\end{array}$ \\
\hline Tryptophan-like & $<250$ & $280-330$ & - & - & - & - & - & - & - & - \\
\hline Tyrosine-like & $<250$ & $330-380$ & $225 / 335$ & 372,800 & $225 / 335$ & 116,496 & $225 / 340$ & 135,568 & $230 / 340$ & 2846 \\
\hline $\begin{array}{l}\text { Soluble microbial } \\
\text { by-product-like }\end{array}$ & $>250$ & $280-380$ & $275 / 340$ & 287,520 & $280 / 340$ & 98,032 & $275 / 335$ & 95,088 & $275 / 335$ & 4632 \\
\hline Humic acid-like & $>250$ & $>380$ & - & - & $285 / 405$ & 100,976 & $265 / 430$ & 91,600 & $260 / 440$ & 2665 \\
\hline Fulvic acid-like & $<250$ & $>380$ & - & - & $240 / 415$ & 113,424 & $240 / 410$ & 103,312 & $245 / 410$ & 2574 \\
\hline
\end{tabular}
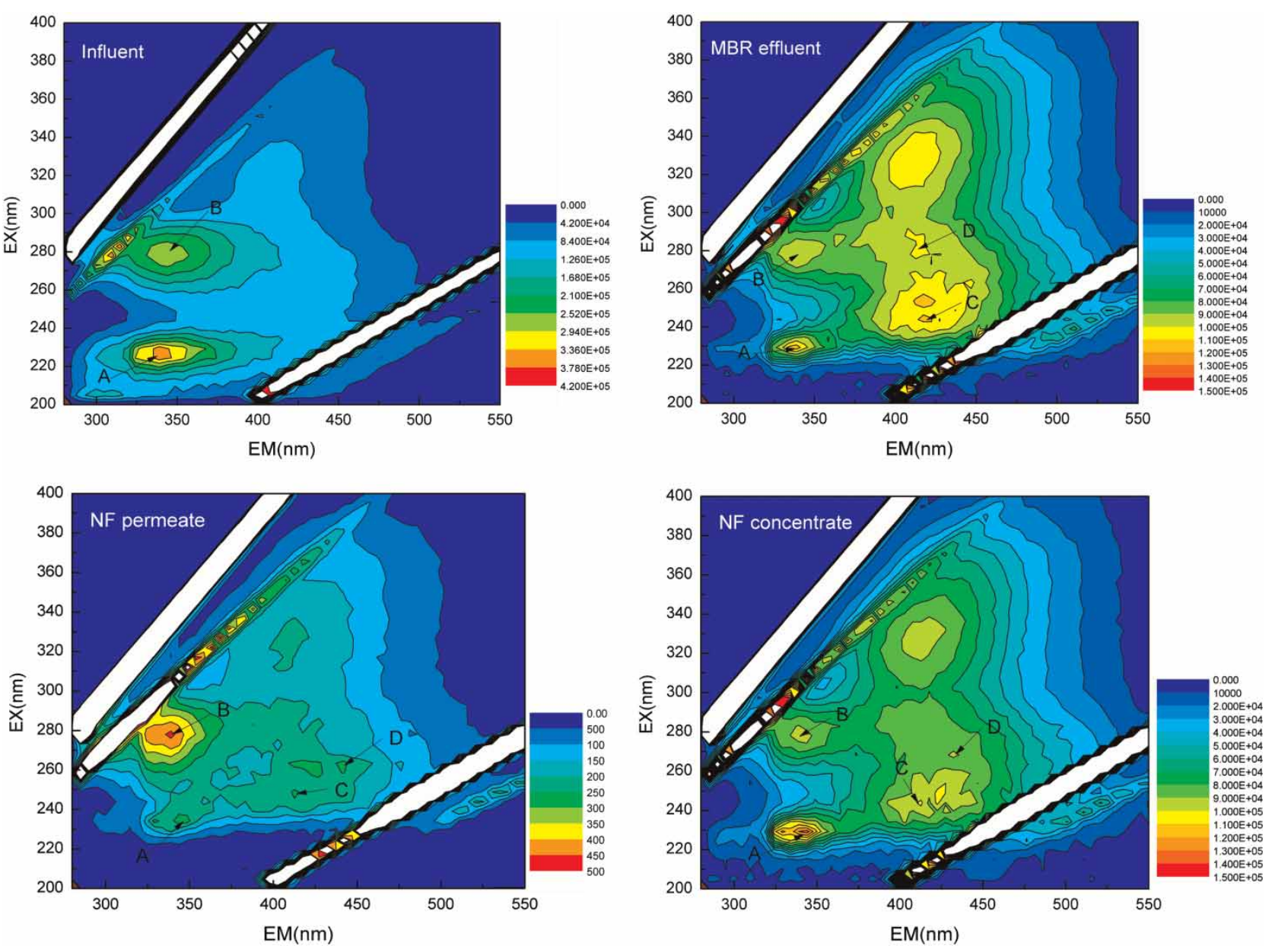

Figure 5 | Fluorescence contour of wastewater in each stage of the pilot MBR-NF.

wastewater. In addition, some parts of these substances may be produced from the anaerobic process before the pilot MBR-NF treatment. After treatment by the MBR unit, the intensity of peaks A and B was significantly weakened. Two new peaks, i.e., peaks $C$ and D, appeared at Ex/Em of 240/ 415 and 285/405 nm in the EEM spectra of MBR effluent; they were associated with fulvic acid-like and humic acidlike substances (Chen et al. 2003). This might be because microorganisms could generate part of the non-biodegradable substances due to the bio-decay effects (Wang et al. 20IO). In the NF concentrate and permeate, there were the same peaks as the MBR influent which showed that the NF 
unit was mainly a filtration process. However, the maximum intensities of each peak of the different wastewaters in the pilot MBR-NF were quite different. The intensity of all the peaks weakened significantly in the NF permeate, which demonstrated that these substances could be perfectly rejected by the NF membrane. The organic substances that accumulated in the NF concentrate were treated and removed by the MBR again through recycling.

\section{CONCLUSIONS}

A pilot MBR-NF system at a high water yield of $92 \pm 5.6 \%$ obtained by recycling the NF concentrate to the MBR tank was carried out to treat real antibiotic wastewater. Recycling of the NF concentrate had no significant impacts on performance of the MBR-NF. The pilot scale system operated in good conditions and obtained excellent water quality in which the concentrations of COD and TOC of the NF permeate were stable at 35 and $5.7 \mathrm{mg} / \mathrm{L}$, respectively. The removal rates of both SPM and NSPM reached over 95\%. Most of the organic pollutants could be reduced through recycling the NF concentrate and only a small part of them was discharged with the NF concentrate and permeate.

\section{ACKNOWLEDGEMENTS}

Financial support provided by the National Major Science \& Technology Projects for Water Pollution Control and Management (No. 2012ZX07203-002) and National High Technology Research and Development Program of China (No. 2009AA063901) are gratefully acknowledged.

\section{REFERENCES}

Alexy, R., Kumpel, T. \& Kummerer, K. 2004 Assessment of degradation of 18 antibiotics in the Closed Bottle Test. Chemosphere 57 (6), 505-512.

Alturki, A. A., Tadkaew, N., McDonald, J. A., Khan, S. J., Price, W. E. \& Nghiem, L. D. 2010 Combining MBR and NF/RO membrane filtration for the removal of trace organics in indirect potable water reuse applications. Journal of Membrane Science 365 (1-2), 206-215.

Amin, M. M., Zilles, J. L., Greiner, J., Charbonneau, S., Raskin, L. \& Morgenroth, E. 2006 Influence of the antibiotic erythromycin on anaerobic treatment of a pharmaceutical wastewater. Environmental Science and Technology 40 (12), 3971-3977.
APHA 1998 Standards Methods for the Examination of Water and Wastewater. 20th edn, American Public Health Association, Washington, DC.

Chelliapan, S., Wilby, T. \& Sallis, P. J. 2006 Performance of an upflow anaerobic stage reactor (UASR) in the treatment of pharmaceutical wastewater containing macrolide antibiotics. Water Research 40 (3), 507-516.

Chen, W., Westerhoff, P., Leenheer, J. A. \& Booksh, K. 2003 Fluorescence excitation - Emission matrix regional integration to quantify spectra for dissolved organic matter. Environmental Science and Technology 37 (24), 5701-5710.

Choi, J. H., Fukushi, K. \& Yamamoto, K. 2008 A study on the removal of organic acids from wastewaters using nanofiltration membranes. Separation and Purification Technology 59 (1), 17-25.

Elmolla, E. S. \& Chaudhuri, M. 2orI Combined photo-Fenton-SBR process for antibiotic wastewater treatment. Journal of Hazardous Materials 192 (3), 1418-1426.

Joss, A., Baenninger, C., Foa, P., Koepke, S., Krauss, M., McArdell, C. S., Rottermann, K., Wei, Y., Zapata, A. \& Siegrist, H. 2011 Water reuse: $>90 \%$ water yield in MBR/RO through concentrate recycling and $\mathrm{CO}_{2}$ addition as scaling control. Water Research 45 (18), 6141-6151.

Kim, S. D., Cho, J., Kim, I. S., Vanderford, B. J. \& Snyder, S. A. 2007 Occurrence and removal of pharmaceuticals and endocrine disruptors in South Korean surface, drinking, and waste waters. Water Research 41 (5), 1013-1021.

Kummerer, K. 20or Drugs in the environment: emission of drugs, diagnostic aids and disinfectants into wastewater by hospitals in relation to other sources - a review. Chemosphere 45 (6-7), 957-969.

Sahar, E., David, I., Gelman, Y., Chikurel, H., Aharoni, A., Messalem, R. \& Brenner, A. 2oIr The use of RO to remove emerging micropollutants following CAS/UF or MBR treatment of municipal wastewater. Desalination 273 (1), 142-147.

Wang, K. L., Liu, S. Q., Zhang, Q. \& He, Y. L. 20oga Pharmaceutical wastewater treatment by internal microelectrolysis-coagulation, biological treatment and activated carbon adsorption. Environmental Technology 30 (13), 1469-1474.

Wang, Z. W., Wu, Z. C. \& Tang, S. J. 20ogb Extracellular polymeric substances (EPS) properties and their effects on membrane fouling in a submerged membrane bioreactor. Water Research 43 (9), 2504-2512.

Wang, Z. W., Tang, S. J., Zhu, Y. F., Wu, Z. C., Zhou, Q. \& Yang, D. H. 2oro Fluorescent dissolved organic matter variations in a submerged membrane bioreactor under different sludge retention times. Journal of Membrane Science 355 (1-2), 151-157.

Xing, Z. P. \& Sun, D. Z. 2009 Treatment of antibiotic fermentation wastewater by combined polyferric sulfate coagulation, Fenton and sedimentation process. Journal of Hazardous Materials 168 (2-3), 1264-1268. 